\title{
DESEMPENHO, CARACTERÍSTICAS DE CARCAÇA E DA CARNE DE NOVILHAS DA SEXTA GERAÇÃO DO CRUZAMENTO CHAROLÊS X NELORE ABATIDAS AOS 18 MESES DE IDADE
}

\section{PERFORMANCE, CARCASS CHARACTERISTICS AND MEAT OF HEIFERS THE SIXTH GENERATION OF THE CHAROLAIS X NELLORE SLAUGHTERED AT 18 MONTHS OF AGE}

\author{
Leonel da Silva Rodrigues ${ }^{1 *}$ ORCID - http://orcid.org/0000-0002-9272-9151 \\ Dari Celestino Alves Filho ${ }^{1}$ ORCID - http://orcid.org/0000-0003-2559-7504 \\ Ivan Luiz Brondani ${ }^{1}$ ORCID - http://orcid.org/0000-0002-6526-3042 \\ Amanda Farias de Moura1 ORCID - http://orcid.org/0000-0001-8078-6813 \\ Marcelo Ascoli da Silva1 ORCID - http://orcid.org/0000-0001-7683-0711 \\ Camille Carijo Domingues ${ }^{1}$ ORCID - http://orcid.org/0000-0003-1781-7626
}

1 Universidade Federal de Santa Maria, Santa Maria, RS, Brasil.

*Autor para correspondência - rodrigues_leonel@hotmail.com

\section{Resumo}

O objetivo do presente estudo foi avaliar o desempenho, as características quantitativas da carcaça e qualitativas da carne de novilhas de sexta geração oriundas do cruzamento entre as raças Charolês e Nelore abatidas aos 18 meses de idade. Os tratamentos testados foram os grupos genéticos 43/64 Nelore 21/64 Charolês (4364NE) e 43/64 Charolês 21/64 Nelore (4364CH). Foram utilizadas 36 novilhas, com idade média de 15 meses e peso médio inicial de $262 \mathrm{~kg}$ de peso corporal. Os animais foram terminados em pastagem de sorgo forrageiro, recebendo suplementação em nível de 1\% do peso corporal. O grupo genético dos animais não influenciou os seus desempenhos, com ganhos de pesos diários de 0,827 e 0,860 kg para animais 4364NE e 4364CH, respectivamente. As características de carcaça não foram influenciadas pelo grupo genético dos animais, com pesos médios de carcaça quente de 197,46 e 193,19 kg e 56,68\% e 55,63\%, para animais 4364NE e 4364CH, respectivamente. Foram observados para cor, textura, suculência e maciez valores médios entre os tratamentos de 4,41; 4,27; 6,04 e 6,24 pontos, respectivamente. As predominâncias genéticas da sexta geração do cruzamento Charolês x Nelore não afetam as características de desempenho, carcaça e carne de novilhas.

Palavras-chave: ganho de peso, maciez, rendimento de carcaça, sorgo forrageiro, Sorghum bicolor.

\begin{abstract}
The objective of the present study was to evaluate the performance, quantitative characteristics of the carcass and qualitative of the meat of sixth generation heifers from the crossing between the Charolais and Nelore races slaughtered at 18 months of age. The treatments tested were the genetic groups 43/64 Nellore 21/64 Charolais (4364NE) and 43/64 Charolais 21/64 Nellore (4364CH). Thirty-six heifers with a mean age of 15 months and initial mean weight of $262 \mathrm{~kg}$ of body weight were used. The animals were finished in forage sorghum pasture, receiving supplementation at the level of $1 \%$ of body weight. The genetic group of the animals did not influence their performance, with daily weight gains of 0.827 and $0.860 \mathrm{~kg}$ for animals $4364 \mathrm{NE}$ and $4364 \mathrm{CH}$, respectively. The carcass characteristics were not influenced by the genetic group of the animals, with average carcass
\end{abstract}


weights of 197.46 and $193.19 \mathrm{~kg}$ and 56.68 and $55.63 \%$ for $4364 \mathrm{NE}$ and $4364 \mathrm{CH}$, respectively. It was observed for color, texture, juiciness, softness average values between treatments of $4.41 ; 4.27 ; 6.04$ and 6.24 points, respectively. Genetic predominance of the sixth generation of the Charolais $\mathrm{x}$ Nellore cross did not affect the performance, carcass and beef characteristics of heifers.

Key-words: Forage sorghum, yield carcass, weight gain, softness, Sorghum bicolor.

Recebido em 20 de novembro de 2017.

Aceito em 23 de maio de 2018.

\section{Introdução}

O Brasil é o quarto maior exportador mundial de carne bovina, exportando anualmente cerca de 1,2 milhão de toneladas de equivalente carcaça ${ }^{(1)}$. São abatidos anualmente cerca de 42 milhões de cabeças de bovinos, das quais $48,8 \%$ do total de animais são fêmeas, índice este que vem se mantendo constante nos últimos dez anos ${ }^{(1)}$.

Segundo Vaz et al. ${ }^{(2)}$, em sistemas de produção de bezerros com taxas de desmame superiores a $80 \%$, ocorre uma alta produção de bezerros, tanto machos como fêmeas, em função da redução na taxa de reposição de matrizes e do excesso de fêmeas nascidas em relação a essa taxa. Esse fato eleva a participação de fêmeas de descarte na taxa de desfrute das propriedades e de abate nos frigoríficos.

A terminação de animais em idade jovem apresenta a vantagem da melhor eficiência quando comparada à terminação de animais em idade mais avançada ${ }^{(3)}$. Coutinho Filho et al. ${ }^{(3)}$, ao comparar a viabilidade econômica na terminação de machos e fêmeas com idade inferior aos 18 meses de idade, relatam retorno financeiro levemente inferior para a terminação de fêmeas, porém, observamse bons resultados econômicos com a terminação de novilhas jovens ${ }^{(4)}$. Paulino et al. ${ }^{(5)}$, ao estudarem o desempenho produtivo de bovinos Nelore de três condições sexuais distintas, machos inteiros, castrados e fêmeas, relatam maior eficiência alimentar na transformação de alimento em peso de carcaça para fêmeas jovens do que de machos castrados.

Aliado à redução da idade de abate, o cruzamento dos bovinos também é uma ferramenta para aumentar a produtividade. $\operatorname{Koger}^{(6)}$ cita o cruzamento como forma de acelerar os avanços genéticos, ao inserir genes desejáveis mais rapidamente que os métodos de seleção dentro da mesma raça. Ainda de acordo com o autor, a distância genética entre as raças utilizadas no cruzamento é um fator que propicia níveis mais elevados de heterose. Segundo Vaz et al.(7), o cruzamento entre bovinos Bos taurus x Bos indicus é uma alternativa de uso de recursos genéticos que pode aumentar a produção de carne nos rebanhos de corte, aliando os índices produtivos das raças taurinas e a rusticidade das raças zebuínas. Além disso, a utilização de cruzamento rotativo permite explorar a heterozigose, podendo manter no rebanho níveis de heterose individual elevada e possibilitando que as fêmeas de reposição sejam produzidas no próprio sistema.

Este trabalho foi realizado com o objetivo de avaliar o desempenho, as características quantitativas da carcaça e qualitativas da carne de novilhas de sexta geração oriundas do cruzamento entre as raças Charolês e Nelore abatidas aos 18 meses de idade, terminadas em pastagem de sorgo forrageiro associado à utilização de suplementação energética. 


\section{Material e métodos}

O protocolo experimental utilizado no presente estudo foi aprovado pela Comissão de Ética no Uso de Animais da Universidade Federal de Santa Maria (UFSM), aprovado sob o parecer $n^{\circ}$ 128/2014.

O experimento foi realizado na Universidade Federal de Santa Maria, localizada na depressão central do Rio Grande do Sul, no período de 15 de novembro a 11 de abril de 2014. O clima da região é do tipo Cfa (subtropical úmido), conforme classificação de Köppen ${ }^{(8)}$. O solo da área experimental pertence à unidade de mapeamento São Pedro e é classificado como Argissolo Vermelho Distrófico Arênico ${ }^{(9)}$.

Os tratamentos testados foram os grupos genéticos 43/64 Nelore 21/64 Charolês (4364NE) e 43/64 Charolês 21/64 Nelore (4364CH). Foram utilizadas 36 novilhas com idade e peso médio inicial de 15 meses e $262 \mathrm{Kg}$ de peso corporal, respectivamente. As novilhas são pertencentes à sexta geração do cruzamento rotativo alternado entre as raças Charolês $(\mathrm{CH})$ e Nelore $(\mathrm{NE})$, sendo todas oriundas do mesmo rebanho experimental.

Os animais foram terminados em pastagem de sorgo forrageiro (Sorghum bicolor), recebendo suplementação em nível de $1 \%$ do peso corporal, fornecida diariamente às 11 horas da manhã. Os níveis de proteína bruta (PB) e nutrientes digestíveis totais (NDT) do suplemento foram de 144,0 g kg-1 de MS e 767,0 $\mathrm{g} \mathrm{kg}^{-1}$ de MS, respectivamente. Todos os tratamentos receberam o mesmo suplemento, que foi formulado a partir da relação de $62,9 \%$ de grão de aveia branca, $35 \%$ de grão de milho, $1 \%$ de ureia e $1,1 \%$ de calcário calcítico. A forrageira apresentou em média $164,14 \mathrm{~g} \mathrm{~kg}^{-1} \mathrm{de}$ MS de PB e 707,64 $\mathrm{g} \mathrm{kg}^{-1}$ de MS de NDT.

A área experimental utilizada correspondeu a 16,3 ha, sendo 11,7 ha divididos em 12 piquetes com área variável, onde foram manejados os animais-teste, e 4,6 ha, onde permaneceram os animais reguladores. A implantação da pastagem ocorreu no dia 15/11, com a utilização de semeadoura em linha em sistema de plantio direto. Aplicaram-se na base $150 \mathrm{~kg} \mathrm{ha}^{-1}$ de adubo N-P-K, com formulação 5-20-20. A quantidade de nitrogênio aplicada em cobertura foi de $100 \mathrm{~kg} \mathrm{ha}^{-1}$ de ureia, o que correspondeu a $45 \mathrm{Kg} \mathrm{ha}^{-1}$ de nitrogênio, divididos em duas aplicações.

O método de pastoreio utilizado foi contínuo, com taxa de lotação variável ${ }^{(10)}$. A massa de forragem da pastagem foi controlada com o objetivo de manter uma oferta de forragem de $9 \%$ ( $9 \mathrm{Kg}$ de $\mathrm{MS} / 100$ kg de PV).

O critério de abate foi determinado pela espessura de gordura subcutânea na região do músculo Longissimus dorsi (mínima de $3 \mathrm{~mm}$ ), especificamente sobre a $12^{\mathrm{a}}$ e a $13^{\mathrm{a}}$ costelas, com a captação de imagens através do ultrassom ALOKA SSD 500 e a interpretação delas pelo programa BIOTRONIC - BioSoft Toolbox®.

O peso corporal dos animais foi obtido no início e ao final de cada período do experimento, previamente a jejum de 12 horas de sólidos e líquidos, sendo o ganho de peso diário calculado através da divisão da diferença entre as pesagens pelo número de dias dos períodos. Durante as pesagens, foi avaliada a condição corporal dos animais, atribuindo-se pontuação de 1 a 5 , na qual $1=$ muito magra e $5=$ muito gorda, seguindo metodologia descrita por Ferreira et al. ${ }^{(11)}$. O ganho em condição corporal foi obtido pela subtração do escore final do período experimental em relação ao escore corporal inicial do período experimental.

Ao final do período experimental, os animais foram abatidos, em frigorífico comercial, obedecendo 
ao fluxo normal do estabelecimento, após jejum de sólidos e líquidos. Os pesos de carcaça quente e fria foram obtidos logo após o abate, antes da entrada na câmara fria e após o resfriamento das carcaças por 24 horas, respectivamente. Os rendimentos de carcaça quente e fria em \% do peso corporal foram calculados através da divisão dos pesos de carcaça (quente ou fria) pelo peso corporal ao abate e multiplicados por 100 . Todas as avaliações de carcaça foram realizadas após o resfriamento delas. Nas duas meias-carcaças, foram avaliadas a maturidade fisiológica e a conformação, seguindo a metodologia descrita por Leão et al. ${ }^{(12)}$. Na meia-carcaça esquerda, foram separados os cortes comerciais traseiro, dianteiro e costilhar e pesados individualmente para determinação das suas proporções em relação à meia-carcaça, sendo após extrapolados para a carcaça inteira.

$\mathrm{Na}$ meia-carcaça direita, foram obtidas as características métricas: comprimento de carcaça, comprimento da perna, espessura de coxão, comprimento e perímetro de braço.

Para determinar as porcentagens de músculo, gordura e osso, seguiu-se a metodologia descrita por Rezende et al.(13), sendo extraída uma porção do músculo Longissimus dorsi e congelada. Posteriormente, foram extraídas do músculo congelado duas fatias (A e B) de 2,5 cm de espessura perpendicularmente ao comprimento do músculo, as quais foram utilizadas para a avaliação das características sensoriais (fatia A), da quebra ao descongelamento, quebra à cocção e resistência das fibras ao corte (fatia B).

As características sensoriais da carne foram avaliadas conforme metodologia descrita por Leão et al. ${ }^{(12)}$, através da avaliação realizada por painel de degustadores treinados. Para cálculo das perdas ao descongelamento e à cocção, procedeu-se à pesagem da fatia $\mathrm{B}$, ainda congelada, depois de descongelada e após o cozimento, que aconteceu até que a temperatura interna da fatia atingisse $70^{\circ} \mathrm{C}$. Foram extraídas cinco amostras de feixes de fibras com $1 \mathrm{~cm}^{2}$ de área da fatia $\mathrm{B}$, as quais foram utilizadas para a determinação da força de cisalhamento através do aparelho Warner-Bratzler Shear.

O delineamento experimental utilizado foi o inteiramente casualizado. Realizou-se teste de normalidade de Shapiro-Wilk em todas as variáveis, para verificar o comportamento normal dos resíduos. Os dados foram analisados pelo procedimento GLM (Statistical Analysis System - SAS Studio University Edition, versão 3.5). O modelo matemático adotado foi representado por:

$Y i j k=\mu+G+R k(G)+e i j k$

Onde: Yijk representa as variáveis dependentes; $\mu$ a média de todas as observações; $G$ o efeito da predominância genética; $\mathrm{Rk}(\mathrm{G})$ efeito da k-ésima repetição dentro de cada tratamento e o eijk o erro total experimental.

\section{Resultados e discussão}

As variáveis peso inicial, ganho de peso diário, escore de condição corporal inicial e escore de condição corporal final, bem como o ganho em escore de condição corporal não foram influenciados pelo grupo genético (Tabela 1). O ganho de peso obtido em média para os tratamentos, 0,844 $\mathrm{Kg}$ dia $^{-1}$, foi suficiente para os animais atingirem condições de abate ao final dos 84 dias de utilização da pastagem. Esse fato se comprova através da espessura de gordura subcutânea de 3,51 mm (Tabela 4), estando dentro do preconizado pela indústria frigorífica para a espessura de gordura subcutânea de 3 a $6 \mathrm{~mm}^{(4)}$. 
Tabela 1. Peso inicial, ganho de peso, escore de condição corporal inicial, final, ganho em escore de condição corporal de novilhas de corte de diferentes predominâncias genéticas

\begin{tabular}{|c|c|c|c|c|}
\hline \multirow{2}{*}{ Variável } & \multicolumn{2}{|c|}{ Tratamentos } & \multirow{2}{*}{ EP } & \multirow{2}{*}{$\mathbf{P}$} \\
\hline & 4364NE & $4364 \mathrm{CH}$ & & \\
\hline Peso inicial, Kg & 262,73 & 262,79 & 36,79 & 0,997 \\
\hline Ganho de peso, $\mathrm{Kg} \mathrm{dia}^{-1}$ & 0,827 & 0,860 & 0,14 & 0,486 \\
\hline Escore de condição corporal inicial ${ }^{1}$ & 2,89 & 2,88 & 0,21 & 0,883 \\
\hline Escore de condição corporal final ${ }^{1}$ & 3,79 & 3,69 & 0,19 & 0,107 \\
\hline Ganho em escore de condição corporal ${ }^{1}$ & 0,91 & 0,81 & 0,22 & 0,219 \\
\hline
\end{tabular}

${ }^{1}$ Escore de condição corporal: $1=$ muito magro, $5=$ muito gordo; $\mathrm{EP}=$ erro padrão; $\mathrm{P}>0,05$ diferem ao nivel de $5 \%$ de significância.

Os grupos genéticos não diferiram $(\mathrm{P}<0,05)$ quanto a peso de abate, peso de carcaça quente e peso de carcaça fria (Tabela 2). Os resultados verificados são considerados satisfatórios, tendo em vista a idade e o sexo dos animais, pois foram alcançados pesos de carcaça superiores ao mínimo exigido pelo padrão de mercado brasileiro $(180 \mathrm{~kg})^{(14)}$. Dessa forma, pode-se afirmar que esse contexto vem ao encontro ao que o produtor deseja, pois, como visto, o desempenho quanto ao peso de abate não produziu carcaças distintas e que poderiam prejudicar o seu valor econômico (muito magra ou muito leve).

Tabela 2. Peso de abate, peso de carcaça quente e fria e rendimentos de carcaça quente e fria e dos cortes comerciais de novilhas de corte de diferentes predominâncias genéticas

\begin{tabular}{|c|c|c|c|c|}
\hline \multirow{2}{*}{ Variável } & \multicolumn{2}{|c|}{ Tratamentos } & \multirow{2}{*}{$\mathbf{E P}^{\mathbf{l}}$} & \multirow{2}{*}{$\mathbf{P}^{2}$} \\
\hline & $4364 \mathrm{NE}$ & $4364 \mathrm{CH}$ & & \\
\hline \multicolumn{5}{|c|}{ Pesos de carcaça e cortes comerciais- } \\
\hline Peso de abate, $\mathrm{kg}$ & 335,73 & 339,38 & 39,65 & 0,790 \\
\hline Peso de carcaça quente, $\mathrm{kg}$ & 197,46 & 193,19 & 24,38 & 0,615 \\
\hline Peso de carcaça fria, $\mathrm{kg}$ & 193,13 & 188,95 & 24,13 & 0,619 \\
\hline Dianteiro, kg & 36,91 & 34,66 & 4,82 & 0,175 \\
\hline Traseiro, kg & 54,99 & 53,87 & 6,54 & 0,622 \\
\hline Costilhar, kg & 10,60 & 10,54 & 1,62 & 0,915 \\
\hline \multicolumn{5}{|c|}{ Rendimentos de carcaça e cortes comerciais } \\
\hline Rendimento de carcaça quente, $\% \mathrm{PC}^{3}$ & 56,68 & 55,63 & 1,81 & 0,087 \\
\hline Rendimento de carcaça fria, \% PC & 55,43 & 54,40 & 1,82 & 0,096 \\
\hline Dianteiro, $\% \mathrm{PCF}^{4}$ & 36,05 & 34,92 & 1,70 & 0,051 \\
\hline Traseiro, \% PCF & 53,61 & 54,46 & 1,63 & 0,123 \\
\hline Costilhar, \% PCF & 10,34 & 10,61 & 0,70 & 0,273 \\
\hline
\end{tabular}

Os rendimentos de carcaça quente e fria não foram influenciados pelos grupos genéticos, com valores de 56,68; 55,43 e 55,63; 54,40\% para predominância $\mathrm{NE}$ e $\mathrm{CH}$, respectivamente. Esses rendimentos são considerados bons, e o fato de ter maior participação de sangue $\mathrm{CH}$ não afetou o rendimento no tratamento $4364 \mathrm{CH}$, o que é desejável. Wheeler et al. ${ }^{(15)}$, ao estudarem características de carcaça de diferentes genótipos, concluíram que, para uma mesma idade e grau de acabamento, o peso de carcaça é maior para os filhos de touros $\mathrm{CH}$. Já animais filhos de touros NE apresentam maior rendimento de 
carcaça. Porém, no presente estudo em animais da sexta geração, a maior proporção de sangue, tanto das raças $\mathrm{CH}$ como $\mathrm{NE}$, não resultou em efeito significativo nas características referidas, o que pode estar relacionado à estabilização na heterozigose em gerações avançadas do cruzamento.

Os grupos genéticos não influenciaram os pesos absolutos dos cortes comerciais primários. O mesmo pode ser observado para os pesos relativos de traseiro, dianteiro e costilhar. Em média para os grupos genéticos, foram observados peso de dianteiro, traseiro e costilhar de 35,$79 ; 54,43 ; 10,57$ $\mathrm{Kg}$, respectivamente. Nesse sentido, autores como Climaco et al. ${ }^{(16)}$, ao estudarem as raças Tabapuã, Bonsmara e os cruzamentos Bonsmara x Nelore e Bonsmara x Red Angus x Nelore, e Bianchini et al. ${ }^{(17)}$, ao estudarem o cruzamento entre as raças Simental x Nelore, também não relatam influência dos grupos genéticos nos pesos dos cortes comerciais. Coutinho Filho et al. ${ }^{(4)}$, estudando novilhas da raça Santa Gertrudis terminadas em confinamento e abatidas com idade de abate semelhante ao do presente estudo, relatam pesos absolutos para dianteiro, traseiro e costilhar de 35,67; 50,02; 14,31 Kg, respectivamente, valores semelhantes ao encontrados no presente estudo, indicando que o sistema alimentar e a raça não afetam a composição de cortes comerciais na referida categoria animal.

O peso relativo de dianteiro em relação ao peso de carcaça fria foi semelhante entre os grupos genéticos, os valores observados para os animais do grupo genético 4364NE e 4364CH foram de $36,05 \%$ e $34,92 \%$, respectivamente. Restle et al. ${ }^{(18)}$ não observaram diferenças significativas para peso relativo de dianteiro em vacas de descarte, comparando os grupos genéticos $\mathrm{CH}, 3 / 4 \mathrm{CH}+1 / 4 \mathrm{NE}$ e $1 / 2 \mathrm{CH}+1 / 2 \mathrm{NE}$.

O grupo genético não influenciou as variáveis Comprimento de Carcaça, Comprimento de Perna, Comprimento de Braço, Perímetro de Braço, Espessura de Coxão e Compacidade da Carcaça (Tabela $3)$. Era de se esperar que, no grupo genético 4364NE, as características métricas da carcaça estudadas fossem significativamente maiores, devido à raça Nelore ser um tipo mais longilíneo, mas isso não ficou evidenciado. Segundo Ferreira et al. ${ }^{(19)}$, a participação da raça NE em cruzamentos aumenta o comprimento dos membros, porém, neste estudo, não foram observadas diferenças no comprimento de braço e no comprimento de perna entre os grupos genéticos avaliados.

Tabela 3. Comprimentos de carcaça, perna, braço, perímetro de braço, espessura de coxão e compacidade de carcaça de novilhas de corte de diferentes predominâncias genéticas

\begin{tabular}{lccccc}
\hline \multirow{2}{*}{ Variável } & \multicolumn{2}{c}{ Tratamentos } & \multirow{2}{*}{ EP } & \multirow{2}{*}{ P } \\
\cline { 2 - 3 } & $\mathbf{4 3 6 4 N E}$ & $\mathbf{4 3 6 4 C H}$ & & \\
\hline Comprimento de carcaça, cm & 113,53 & 116,80 & 7,97 & 0,236 \\
Comprimento de perna, cm & 64,78 & 66,35 & 7,57 & 0,548 \\
Comprimento de braço, cm & 34,63 & 34,03 & 1,83 & 0,340 \\
Espessura de coxão, cm & 24,65 & 23,38 & & 2,88 & 0,199 \\
Perímetro de braço, cm & 33,15 & 33,78 & & 2,23 & 0,421 \\
Conformação, pontos & 8,40 & 8,75 & 1,12 & 0,367 \\
Maturidade, pontos & 14,20 & 14,10 & & 0,60 & 0,633 \\
Compacidade da carcaça, cm Kg & -1 & 1,69 & 1,61 & 0,20 & 0,295 \\
\hline
\end{tabular}

$\mathrm{EP}=$ erro-padrão; $\mathrm{P}>0,05$ diferem ao nivel de $5 \%$ de significância.

Ferreira et al. ${ }^{(19)}$, ao estudarem o efeito do grupo genético sobre as características de carcaça de vacas de descarte, não observaram influência dele sobre a conformação e a maturidade. Ainda de acordo com os autores, a participação da raça $\mathrm{CH}$ em cruzamentos aumenta a expressão muscular das carcaças, devido às características da raça de alta expressão muscular. No entanto, a geração 
do cruzamento $\mathrm{CH}$ x NE estudada não apresenta essa característica, o que pode estar relacionado à estabilização na heterozigose observada em cruzamentos rotativos alternados de duas raças a partir da quinta geração.

As variáveis Espessura de Gordura Subcutânea e Área de Olho de Lombo não foram influenciadas pelos grupos genéticos (Tabela 4). Foram obtidos valores de EGS de 3,45 e 3,57 mm para os animais do grupo genético $4364 \mathrm{NE}$ e $4364 \mathrm{CH}$. A ausência de diferenças significativas para essas duas características é desejável, pois, devido às duas predominâncias genéticas, era de se esperar no grupo 4364NE uma menor área de olho de lombo e, no grupo $4364 \mathrm{CH}$, uma menor espessura de gordura subcutânea. Esse equilíbrio verificado atende principalmente ao mercado consumidor, com uma maior padronização dos cortes. Os animais apresentaram área de olho de lombo média de 42,78 $\mathrm{cm}^{2}$, valores semelhantes aos relatados por Coutinho Filho et al. ${ }^{(3)}$ para fêmeas abatidas aos 18 meses de idade, 45,67 cm², em função da semelhança do peso de abate em ambos estudos, e inferiores aos reportados por Vaz et al.(2), 52,4 $\mathrm{cm}^{2}$, para novilhas abatidas aos 14 meses de idade, o que pode estar atrelado à maior conformação relatada pelos autores em comparação ao presente estudo.

Tabela 4. Peso total e relativo de músculo, gordura e osso na carcaça, e proporções entre os tecidos de novilhas de corte de diferentes predominâncias genéticas

\begin{tabular}{lcccc}
\hline \multirow{2}{*}{ Variável } & \multicolumn{2}{c}{ Tratamentos } & \multirow{2}{*}{ EP } & P \\
\cline { 2 - 3 } & $\mathbf{4 3 6 4 N E}$ & $\mathbf{4 3 6 4 C H}$ & & \\
\hline Espessura de gordura subcutânea, mm & 3,45 & 3,57 & 1,03 & 0,741 \\
Área de olho de lombo, cm ${ }^{2}$ & 42,54 & 43,01 & 3,85 & 0,726 \\
Músculo, Kg & 114,35 & 121,10 & 21,85 & 0,374 \\
Músculo, \% Carcaça fria & 59,38 & 64,18 & 8,81 & 0,111 \\
Gordura, Kg & 47,19 & 38,16 & 17,18 & 0,126 \\
Gordura, \% Carcaça fria & 24,22 & 19,99 & 7,52 & 0,100 \\
Osso, Kg & 29,86 & 31,07 & 5,64 & 0,539 \\
Osso,\% Carcaça fria & 16,54 & 16,53 & 1,10 & 0,968 \\
Relação músculo/osso & 3,71 & 3,91 & 0,41 & 0,162 \\
Relação músculo/gordura & 3,15 & 3,33 & 0,82 & 0,536 \\
Relação (músculo+gordura)/osso & 4,97 & 5,13 & 0,56 & 0,411 \\
\hline
\end{tabular}

$\mathrm{EP}=$ erro-padrão; $\mathrm{P}>0,05$ diferem ao nivel de $5 \%$ de significância.

A equidade de respostas entre os grupos genéticos leva à conclusão de que, apesar do desequilíbrio racial (65,6 e 34,4\%), essas respostas são boas, principalmente na condição de meio em que não é feita seleção de fêmeas para terminação no cruzamento em questão (CH vs NE).

A composição genética não influenciou $(\mathrm{P}>0,05)$ as quantidades totais e relativas de músculo, osso e gordura na carcaça. Os valores médios observados para a composição de músculo, gordura e osso foram de 59,$38 ; 24,22 ; 16,54 \mathrm{~kg} 100^{-1}$ carcaça fria, respectivamente, para as novilhas com predominância NE e 64,$18 ; 19,99 ; 16,53 \mathrm{~kg} 100^{-1}$ carcaça fria, respectivamente, para as novilhas com predominância $\mathrm{CH}$. Os resultados observados estão de acordo com os relatados na literatura para novilhas abatidas em idade jovem. Vaz et al. ${ }^{(2)}$, ao estudarem as características de carcaça e carne de novilhas terminadas em pastagem de milheto (Pennisetum purpureum) abatidas aos 14 meses de idade, observaram valores de $58,8 \%$ de músculo, $23,9 \%$ de gordura e $16,9 \%$ de osso.

A semelhança entre os grupos genéticos para o percentual de músculo, gordura e osso refletiu-se 
nas relações músculo/osso, músculo/gordura e músculo+gordura/osso, as quais não diferiram entre os grupos genéticos estudados. Restle et al. ${ }^{(20)}$ também não observaram diferenças significativas nas relações entre os tecidos de novilhas de descarte abatidas aos três anos de idade dos grupos genéticos $\mathrm{CH}$ e 3/4 $\mathrm{CH}+1 / 4 \mathrm{NE}$. Para a relação músculo+gordura/osso, os autores observaram valores superiores ao do presente estudo, sendo de 5,97 para os animais do grupo genético $\mathrm{CH}$ e 6,01 para os animais $3 / 4 \mathrm{CH}+1 / 4 \mathrm{NE}$. Os valores obtidos no presente estudo para a relação de músculo/ osso e músculo+gordura/osso são inferiores aos relatados por Restle et al. ${ }^{(20)}$, devido principalmente à menor participação de gordura $(19,99$ vs $21,64 \%)$ na carcaça no presente estudo.

Não houve diferença $(\mathrm{P}>0,05)$ para as características sensoriais da carne em função dos grupos genéticos estudados (Tabela 5). Em média, os valores obtidos de 4,41 pontos para cor e 4,27 pontos para a textura indicam uma carne com coloração considerada vermelha, com textura fina. Para as características palatabilidade, suculência e maciez, foram observados valores médios entre os tratamentos de 5,$99 ; 6,04 ; 6,24$ pontos respectivamente, o que caracteriza a carne com qualidade levemente acima da média.

Tabela 5. Características sensoriais, perdas ao descongelamento e a cocção, características organolépticas e força de cisalhamento da carne de novilhas de corte de diferentes predominâncias genéticas

\begin{tabular}{|c|c|c|c|c|}
\hline \multirow{2}{*}{ Variável } & \multicolumn{2}{|c|}{ Tratamentos } & \multirow{2}{*}{ EP } & \multirow{2}{*}{$\mathbf{P}$} \\
\hline & 4364NE & $4364 \mathrm{CH}$ & & \\
\hline Cor, pontos ${ }^{1}$ & 4,27 & 4,55 & 0,56 & 0,139 \\
\hline Textura, pontos ${ }^{2}$ & 4,13 & 4,40 & 0,62 & 0,214 \\
\hline Marmoreio, pontos ${ }^{3}$ & 3,67 & 4,20 & 1,60 & 0,336 \\
\hline Palatabilidade, pontos ${ }^{4}$ & 5,96 & 6,02 & 0,43 & 0,668 \\
\hline Suculência, pontos ${ }^{4}$ & 6,09 & 5,99 & 0,65 & 0,669 \\
\hline Maciez, pontos ${ }^{4}$ & 6,14 & 6,34 & 0,78 & 0,472 \\
\hline Força de cisalhamento, $\mathrm{Kgf}^{-3}$ & 7,13 & 6,53 & 1,50 & 0,237 \\
\hline 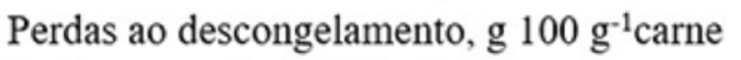 & 9,57 & 10,33 & 1,77 & 0,207 \\
\hline Perdas a cocção, g $100 \mathrm{~g}^{-1}$ carne & 29,46 & 27,62 & 3,39 & 0,108 \\
\hline \multicolumn{5}{|c|}{$\begin{array}{l}{ }^{3} \text { Marmoreio: } 1 \text { a } 3=\text { traços; } 4 \text { a } 6=\text { leve; } 7 \text { a } 9=\text { pequeno; } 10 \text { a } 12=\text { médio; } 13 \text { a } 15=\text { moderado; } 16 \text { a } 18= \\
\text { abundante } \\
{ }^{4} 1=\text { extremamente dura, extremamente sem sabor ou extremamente sem suculência; } 2=\text { muito dura, } \\
\text { deficiente em sabor ou deficiente em suculência; } 3=\text { dura, pouco saborosa ou pouco suculenta; } 4= \\
\text { levemente abaixo da média; } 5=\text { média; } 6=\text { levemente acima da média; } 7=\text { macia, saborosa ou } \\
\text { suculenta; } 8=\text { muito macia, muito saborosa ou muito suculenta; } 9=\text { extremamente macia, extremamente } \\
\text { saborosa ou extremamente suculenta. }\end{array}$} \\
\hline
\end{tabular}

Os valores observados para as características sensoriais da carne são um indicativo da qualidade da carne produzida pelo cruzamento entre as raças $\mathrm{CH} \times \mathrm{NE}$. Vaz et al. ${ }^{(2)}$, ao estudarem as características sensoriais da carne de novilhos e novilhas da raça Braford abatidos com idade de 14 meses, obtiveram para cor da carne, palatabilidade, suculência e maciez valores de 4,58 e 4,50; 6,11 e 5,92; 5,67 e 5,14; 6,00 e 6,06 para machos e fêmeas, respectivamente, valores semelhantes aos observados no presente estudo. Assim como as demais características qualitativas da carne, foi observada similaridade na força de cisalhamento, além de perdas tanto ao descongelamento quanto à cocção nos genótipos estudados. Restle et al. ${ }^{(18)}$ relatam similaridade na força de cisalhamento e perdas ao descongelamento e cocção na carne de vacas de descarte $3 / 4 \mathrm{C}+1 / 4 \mathrm{~N}, 1 / 2 \mathrm{C}+1 / 2 \mathrm{~N}$ e Charolesa pura terminadas em 
confinamento, indicando que o cruzamento entre as raças Charolês e Nelore não alteram as referidas variáveis na primeira geração, na segunda geração e na sexta geração do cruzamento, que é alvo do presente estudo.

\section{Conclusões}

As predominâncias genéticas não afetam as características de desempenho, carcaça e carne de novilhas da sexta geração do cruzamento Charolês x Nelore, quando criadas e abatidas em sistemas intensivos de pecuária de corte.

\section{Referências}

1. Kist BB, Santos CE, Carvalho C, Treichel M. Anuário brasileiro da pecuária. Ed. Beling R.R., Santa Cruz do Sul-RS: Gazeta; 2017. 56 pp. Disponível em: http://www.editoragazeta.com.br/flip/anuario-pecuaria-2017/ files/assets/basic-html/toc.html. Português.

2. Vaz F N, Restle J, Arboite MZ, Pascoal LL, Alves Filho DC, Pacheco R.F. Características de carcaça e da carne de novilhos e novilhas superjovens, terminados com suplementação em pastagem cultivada. Ciência Animal Brasileira, v.11, n. 1, p.42-52, 2010a. Disponível em: https://www.revistas.ufg.br/vet/article/ view/5131/7607? journal=vet. Português.

3. Coutinho Filho JL V, Pere RM, Justo CL. Produção de carne de bovinos contemporâneos, machos e fêmeas, terminados em confinamento. Revista Brasileira de Zootecnia, v. 35, n. 5, p. 2043-2049, 2006. Disponível em: http://www.scielo.br/pdf/\%0D/rbz/v35n5/23.pdf. Português.

4. Vaz FN, Restle J, Arboitte MZ, Pascoal LL, Faturi C, Joner G. Fatores relacionados ao rendimento de carcaça de novilhos ou novilhas superjovens, terminados em pastagem cultivada. Ciência Animal Brasileira, v.11, n. 1, p. 53-61, 2010b. Disponível em: https://www.revistas.ufg.br/vet/article/view/6747/7610?journal=vet. Português.

5. Paulino PVR, Valadares Filho SC, Detmann E, Valadares RFD, Fonseca MA, Véras RML, Oliveira DM. Desempenho produtivo de bovinos Nelore de diferentes classes sexuais alimentados com dietas contendo dois níveis de oferta de concentrado. Revista Brasileira de Zootecnia, v. 37, n. 6, p. 1079-1087, 2008. Disponível em: http://agris.fao.org/agris-search/search.do?recordID=XS2008280619. Português.

6. Koger M. Effective crossbreeding systems utilizing zebu cattle. Journal of Animal Science, v. 50, n. 6, p. 12131220, 1980. Disponível em: https://dl.sciencesocieties.org/publications/jas/abstracts/50/6/JAN0500061215. Inglês.

7. Vaz FN, Restle J, Flores JLC, Pacheco PS, Ávila MM, Pascoal LL, Vaz RZ, Vaz MAB. Qualidade da carcaça e da carne de bovinos superjovens de diferentes grupos genéticos. Revista Agrarian, v.7, n.24, p.319-327, 2014. Disponível em: http://ojs.ufgd.edu.br/index.php/agrarian/article/view/2274. Português.

8. Alvares C A, Stape, JL, Sentelhas PC et al. Köppen's climate classification map for Brazil. Meteorologische Zeitschrift, v.22, p.711-728, 2013. Disponível em: http://www.leb.esalq.usp.br/agmfacil/artigos/artigos sentelhas_2013/2013 MeteorolZeitsch_22(6) 711-728_KoppensClimateClassBrazil.pdf. Inglês.

9. Streck EV, Kämpf N, Dalmolin RSD et al. Solos do Rio Grande do Sul. UFRGS, Departamento de Solos, Faculdade de Agronomia. 2008. Português. 
10. Calvano MPCA., Euclides VPB., Montagner DB, Lempp B, Difante GS, Flores RS, Galbeiro S. Tillering and forage accumulation in Marandu grass under different grazing intensities. Revista Ceres, v. 58, n.6, p.781789, 2011. Disponível em: http://www.scielo.br/scielo.php?pid=S0034-737X2011000600015\&script=sci= arttext\&tlng=es. Inglês.

11. Ferreira MCN, Miranda R, Figueiredo MA, Costa OM, Palhano H B. Impact of body condition on pregnancy rate of cows nellore under pasture in fixed time artificial insemination (tai) program. Semina: Ciências Agrárias, v.34, n.4, p.1861-1868, 2013. Disponível em: http://www.uel.br/revistas/uel/index.php/ semagrarias/article/view/11024. Português.

12. Leão JP, Neiva JNM, Restle J, Míssio RL, Paulino, PVR, Miotto, FRC, Santana, AEM, Sousa, LF, Alexandrino, E. Carcass and meat characteristics of different cattle categories fed diets containing crude glycerin. Semina: Ciências Agrárias, v. 34, n. 1, p. 431-444, 2013. Disponível em: https://www.cabdirect.org/ cabdirect/abstract/20133105725. Português.

13. Rezende PLP, Restle J, Fernandes JJR, Freitas Neto MD, Prado CS, Pereira MLR. Carcass and meat characteristics of crossbred steers submitted to different nutritional strategies at growing and finishing phases. Ciência Rural, v.42, n.5, p.875-881, 2012. Disponível em: http://www.scielo.br/scielo.php?pid=S0103$\underline{84782012000500019 \& \text { script }=\text { sci_arttext\&tlng=pt. Inglês. }}$

14. Felício PE. Perspectivas para a tipificação de carcaça bovina. In: SIMPÓSIO NTERNACIONAL SOBRE TENDÊNCIAS E PERSPECTIVAS DA CADEIA PRODUTIVA DA CARNE BOVINA - SIMPOCARNE, 1999, São Paulo. Anais... São Paulo, SP: nl., 1999. Disponível em: http://www.fea.unicamp.br/deptos/dta/ carnes/files/ Simpocarne1.pdf. Português.

15. Wheeler TL, Cundiff LV, Shackelford SD, Koohmaraie M. Characterization of biological types of cattle (Cycle VII): carcass, yield, and longissimus palatability traits. Journal of Animal Science, v.83, p.196-207, 2005. Disponível em: https://www.ars.usda.gov/ARSUserFiles/30400510/2005010196.pdf. Inglês.

16. Climaco SM, Ribeiro ELA, Rocha MA, Mizubuti IY, Silva LDF, Noro LY, Turini T. Características de carcaça e qualidade de carne de bovinos inteiros ou castrados da raça Nelore, suplementados ou não durante o primeiro inverno. Ciência Rural, v.36, n.6, nov-dez, 2006. Disponível em: http://www.scielo.br/pdf/\%0D/cr/ v36n6/a31v36n6.pdf. Português.

17. Bianchini W, Silveira AC, Jorge AM, Arrigoni MB, Martins CL, Rodrigues E, Hadlich JC, Andrighetto C. Efeito do grupo genético sobre as características de carcaça e maciez da carne fresca e maturada de bovinos superprecoces. Revista Brasileira de Zootecnia, v.36, n.6, p.2109-2117, 2007 (supl.). Disponível em: http:// www.scielo.br/pdf/rbz/v36n6s0/22.pdf. Português.

18. Restle J, Vaz FN, Bernardes RAC, Pascoal LL, Menezes LFG, Pacheco PS. Características de carcaça e da carne de vacas de descarte de diferentes genótipos charolês x nelore, terminadas em confinamento. Ciência Rural, v.33, n.2, p.345-350, 2003. Disponível em: http://www.scielo.br/pdf/\%0D/cr/v33n2/15227.pdf. Português.

19. Ferreira JJ, Menezes LFG, Restle J, Brondani IL, Alves Filho DC, Callegaro AM. Características de carcaça de vacas de descarte e novilhos mestiços Charolês $\times$ Nelore em confinamento sob diferentes frequências de Alimentação. Revista Brasileira de Zootecnia, v.38, n.10, p.1974-1982, 2009. Disponível em: http://agris.fao. org/agris-search/search.do?recordID $=$ XS2009U00301. Português.

20. Restle J, Cerdótes L, Vaz FN, Brondani IL. Características de Carcaça e da Carne de Novilhas Charolês e 3/4 Charolês 1/4 Nelore, terminadas em Confinamento. Revista Brasileira de Zootecnia, v. 30, n. 3, p. 10651075, 2001. Disponível em: http://www.scielo.br/pdf/\%0D/rbz/v30n3s1/5527.pdf. Português. 